\title{
The influence of the strategy of acquisition on uncertainties of measurement of a machined surface
}

\author{
Hassina Gheribi*, Salim Boukebbab** \\ *University of 20 August 55 Skikda, Mechanical department of Engineering, Algeria, E-mail: gheribi_hassina@yahoo.fr \\ **University of Mentouri Constantine, laboratory of Engineering Transport and environment, Algeria, \\ E-mail: boukebbab@yahoo.fr
}

cross $^{\text {ref }}$ http://dx.doi.org/10.5755/j01.mech.23.3.14382

\section{Introduction}

The improvement of quality is that products or processes became a major concern of the industrial companies. To take up this challenge, impose the companies to better control the measuring instruments, which they use. Today a Coordinate Measuring Machine (CMM) is presented in industry, and with the increased technological development, the associated software is in perpetual evolution.

The principle of the software of the Coordinate Measuring Machine (CMM) consists to associate individually each palpated surface with an elementary ideal model (plane, cylinder, cone... etc.) [1]. The latter is characterized by the intrinsic parameters and the topological parameters (situations: position, orientation); the set of these characteristics makes it possible to the geometric element to adapt to the set of the measured points. Therefore, the general problem posed in three-dimensional metrology is the estimate of, the orientation, location and intrinsic parameters of a surface in a reference mark. The association of a theoretical surface to the set of the palpated points based on the calculation of the distances $e_{i}$ between the palpated points and nominal surface obtained by CAD (Computer Aided Design) software.

Obtaining the equation of $e_{i}$ can take various aspects according to the selected hypothesis. If the hypothesis of small displacements is retained, then, a torsor represents the relative position and the orientation of associated surface compared to a local reference mark [2]. If great displacements are used, a matrix based on conventions of the angles of Euler or vectorial rotation is used [2]. In this case, the situation of surface is known in absolute in the basic reference frame.

During control or of checking the part on these machines, surfaces must be measured by a number of points higher than the parameters necessary to their mathematical definitions. However, the representation of the same element can be very different according to the average materials and the protocol used during the measuring operation. For example, on traditional CMMs the acquisition will never give the exact topology of the real measured surface, but only give an image close to the real surface.

Moreover, the real contact points $(i$ or $i+1)$ between the stylus and the measured surface being unknown, one substitutes to it a measured point. This last is calculated starting from co-ordinates of the stylus center, the normal vector $\left(n_{i}\right)$ and the stylus radius, which generates uncertainty on the real position of the measured point (Fig. 1), and which is even propagated on the parameters of associated surface. This uncertainty cannot be obtained with the method of small displacements (linearity of the equation $e_{i}$ ) adapted in the software of CMM, because the major advantage of this method of is accelerated the iterative calculation of minimization and to decrease the computing time. In great displacements (nonlinear), the distance $e_{i}$ calculated does not undergoes any approximation [2], This implies a better estimate of measurement uncertainties compared to the method of small displacements.

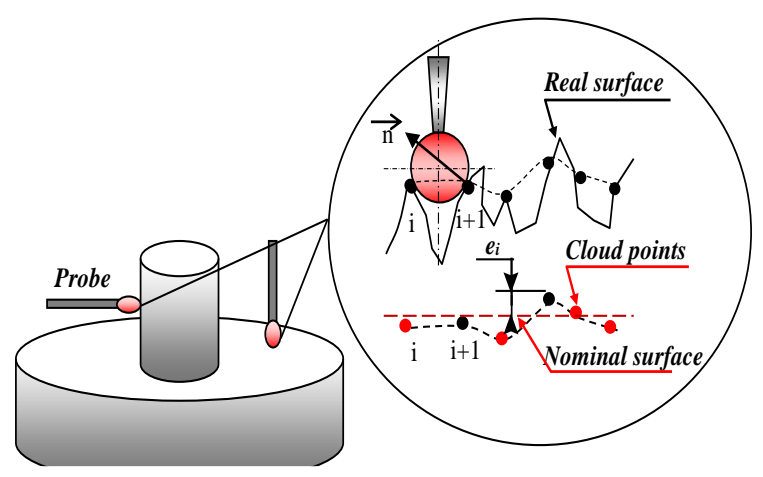

Fig. 1 Representation of real

The estimated dimensional measurement uncertainty in a processing chain of CMM is a relatively new subject. In recent years, many researchers have tried to develop methods for determining uncertainties [3, 9]. However, these approaches on the CMM (Coordinate Measuring Machines) remain at a stage where the knowledge to make of the intervening is not negligible. Among the works that have been performed to evaluate the measurement uncertainty of the measuring machine, there are three possible ways [10], which can be summarized as follows (Fig. 2).

The first consists of using a virtual model of coordinate measuring machine (CMM) and metrology software to simulate the uncertainties on the magnitude to be checked. In general, this approach use the Monte Carlo method to simulate the random influential variables of the measurement process. The second way is an analytical method that consists in using the uncertainties stemming from the calibration (machine geometry, calibration of the stylus ...) and of the measurement, then propagate them in the measurement range until the magnitude has checked. Finally, there are experimental methods, described particularly in the series of ISO 5725 standards that avoid modeling the measurement process. 


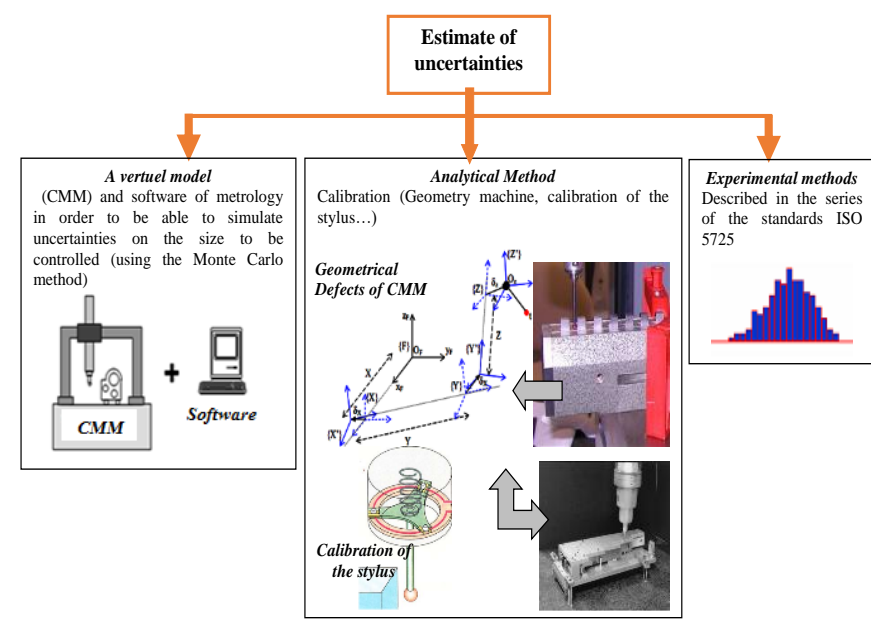

Fig. 2 Various methods for the estimate of uncertainties in a CMM

\section{Concept of uncertainty of measurement}

Metrology is based on the concepts of uncertainty and true value as illustrated by the Fig. 3 . The true value, which would be given by a complete connection to the primary Gauge standards.

Uncertainty measures the dispersion of the measurements around the announced value. It will account how we measured a magnitude. So uncertainty is used to evaluate the confidence, which can grant to a result. Therefore, it is used for the decision-making.

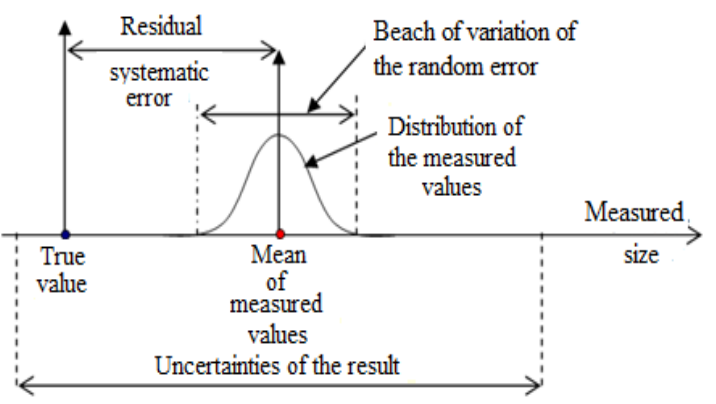

Fig. 3 Basic concepts of metrology

The determination of the uncertainty of measurement starts with the establishment of all the possible factors of influence. A method described in the Guide to Uncertainty in Measurement (GUM) indicates how uncertainties due to all these factors can be take into account to constitute an uncertainty of total measurement [12]. For example in the case of the coordinate measuring machines, the factors of influence can be divide into five fields: CMM material, the environment, the part, the strategy of palpation and the strategy of evaluation in the paragraph precede. The material and the environment present a certain interdependence (dilation of metal according to the temperature). The part and the strategy of palpation are also narrowly overlapping because the number of points of measurement and their site must be selecting accorded to the nature of the parts. For evaluation strategy, refers to the method that is chosen during the consideration of measured values such as filtering data and suitability criteria. This is an area that is often given little attention because the algorithms are in the machine software, but which can exert some influence on the measurement uncertainty.

\subsection{Source of uncertainties of measuremen}

Several sources of errors affect the quality of measurement on a CMM [11]. Among the principal sources of errors:

- Incomplete definition of the measurand;

- Imperfect realization of the definition of the measurand;

- Insufficient knowledge of the effects of the environmental conditions on the measuring or imperfect measuring of the environmental conditions;

- finished resolution of the instrument or threshold of mobility;

- Inaccurate values of the standards and materials of reference; feeler... etc.

Figure. 4 presents the various factors influencing the process of measurement

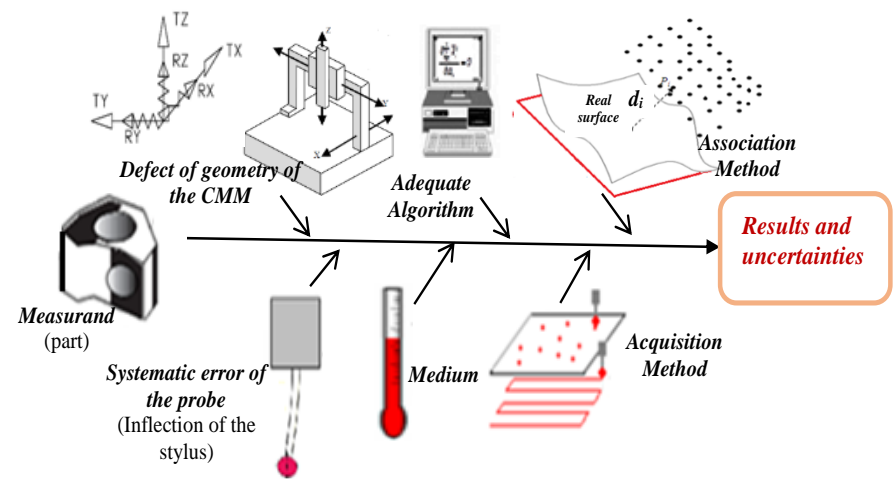

Fig. 4 Source of uncertainties of measurement

2.2. Propagation of uncertainties

Composed in many cases, the measurand $y$ is not measured directly, but is determined from input quantities $x_{i}$ by a measurement function:

$$
y=f\left(x_{1}, x_{2}, \ldots \ldots \ldots x_{\mathrm{n}}\right) .
$$

The standard uncertainties for the input estimates are noted as $u\left(x_{i}\right)$. If the input quantities are independent, the combined standard uncertainty $u(y)$ is obtained from:

$$
u(y)=\sqrt{\sum\left[\frac{\partial f}{\partial x_{i}}\right]^{2} u^{2}\left(x_{i}\right)} .
$$

If measurements of the $x_{i}$ are strongly correlated, calculation is more complex.

$$
u^{2}(y)=\sum_{i=1}^{n}\left[\frac{\partial f}{\partial x_{i}}\right]^{2} \operatorname{Var}\left(x_{i}\right)+2 \sum_{i=1}^{n-1} \sum_{j\rangle i}^{n}\left[\frac{\partial f}{\partial x_{i}}\right]\left[\frac{\partial f}{\partial x_{j}}\right] \operatorname{Cov}\left(x_{i}, x_{j}\right) .
$$


In this law of propagation, it is easier to show the attenuator effect of the term in covariance $u\left(x_{i}, x_{j}\right)$. If one of both derivative partial is negative then this term will decrease the doubt about y.

For a scalar parameter y according to several variables of size $\mathrm{n}$ pertaining to $R^{n}$, the variance can be obtained with the following array formula [9]:

$$
u^{2}(y)=\operatorname{JCov}(A) J^{t},
$$

where $\operatorname{Cov}(A)$ represents the matrix of covariance of $N$ parameters of entries of $x_{i}$ and $J$, the matrix of Jacobian (similar to the calculation of the gradient) defined by

$$
[J]=\left[\frac{\partial y}{\partial x_{1}} \frac{\partial y}{\partial x_{2}} \cdots \frac{\partial y}{\partial x_{i}} \cdots\right],
$$

ith $i=1, n$.

\section{The association methods}

In the case of the association of theoretical surfaces to the groups of points, we present two methods:

\subsection{The torsor of small displacement method}

The torsor of small displacement is obtained by linearizing the matrix of displacement. Nevertheless, the linearization with the first order of the trigonometrically function involves two hypothesis on the validity of the value $\vec{D}_{M}$ :

Hypothesis 1: rotations must be infinitely small $\alpha, \beta$ and $\gamma$ are of order $10^{-04}$

- Hypothesis 2: displacements are feeble [13].

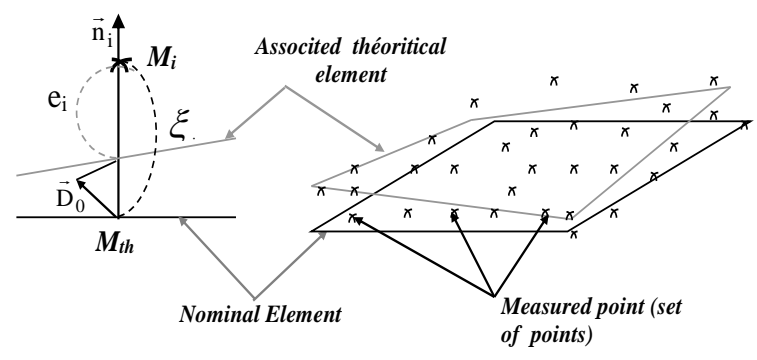

Fig. 5 The small displacement of the theoretical element [14]

The determination of the parameters is carried out by a minimization of the distance between the measured point and the theoretical element (associate) (Fig. 5).

We thus can estimate them by the following vectorial relation [14]:

$$
e_{i}=\xi_{i}-\vec{D}_{M t h} \vec{n}
$$

The part between hooks of the preceding formula represents the torsor of small displacements $\tau$ o and the torsor of the coordinate's plückerienn $\left|P_{\text {tho }}\right|$ of vector $\overrightarrow{n_{i}}$ [15], [16]:

$$
\left|\tau_{0}\right|=\left[\begin{array}{cc}
\vec{\Omega} & \vec{D}_{0} \\
\beta & v \\
\gamma & w
\end{array}\right] \text { and }\left|P_{\text {tho }}\right|=\left\{\begin{array}{c}
\vec{n}_{i} \\
O \vec{M}_{i} \Lambda \vec{n}_{i}
\end{array}\right\} \text {; }
$$

Who can be written in condensed form:

$$
e_{i}=\xi_{i}-\left[\left|\tau_{0}\right| \cdot\left|P_{\text {tho }}\right|\right] \text {. }
$$

\subsection{Nonlinear method (in great displacement)}

The method in great displacement gives us a possibility of knowing the results of optimization in the local reference frame (reference mark part), then in the total reference frame (reference mark machine). In this method the trigonometrically functions of the matrix of rotation are not linearized with the first order, and consequently the assumptions (1) and (2) are not necessary any more. We can speak about a function of variation-optimized $d_{i}$ not linearized [17].
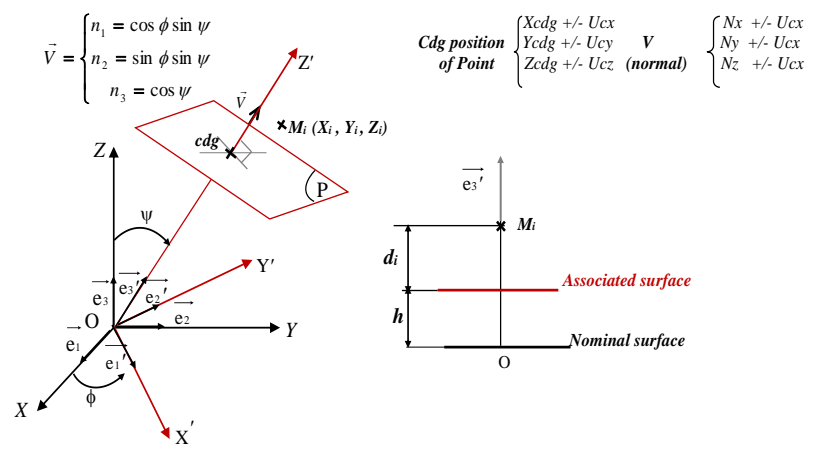

Fig. 6 Modelling for plane [17]

The plane is defined by is normal vector $\mathrm{v}$, this vector is defined in the cylinder coordinate system introducing two angles $(\varphi, \psi)$ and the distance $(h)$ between the plane and the center $O$ of the measurement reference frame

All the parameters are known in the global coordinate system $R_{\mathrm{o}}\left(o, e_{1}, e_{2}, e_{3}\right)$. In this nonlinear method, the distance $d_{i}\left(d_{i}=O \vec{M}_{i} \cdot \vec{n}_{i}-h\right)$ is not subjected to any approximation.

\section{The mathematical tools}

The use of mathematical tools for optimization makes it possible to consider the parameters topographic and intrinsic associated surfaces. This optimization step is often considered a minimization of distances according to a criterion: infinite norm (Tchebichev norm) or (standard least squares) norm $2 \ldots$, (functions based on distances) $\max \left|d_{i}\right|, \quad \sum\left|d_{i}\right|, \quad \sum d_{i}^{2}$, while accurate statistics concepts attached to it.

Whatever the criterion used $\left.{ }^{(\max }\left|d_{i}\right|, \sum\left|d_{i}\right|, \sum d^{2}{ }_{i}\right)$, the estimate $(\psi, \varphi, h)$ of consist in finding the most probable value of these parameters which minimizes the selected criterion. 
The components $(\psi, \varphi, h)$ of the torsor are random variables. They are the components of a random vector $\vec{a}$ of dimension 3 [2].

In three-dimensional metrology and in the case of the vectorial representation of a surface, the random vectors met belong to the maximum with $\mathrm{R}^{6}$. For example, in the case of the cylinder, the random vector will be composed of two parameters of localization and two parameters of orientation and an intrinsic parameter (ray).

The optimization according to the least squares method for distance $d_{i}$ enables us identify the attributes of the fitted surfaces thanks to the following relation:

$$
d_{i}=O \vec{M}_{i} \cdot \vec{n}_{i}-h \Rightarrow \frac{\partial \sum_{i=1}^{n} d_{i}^{2}}{\partial a_{k}}=0,
$$

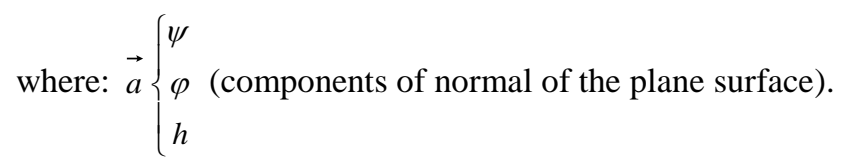

However, the problem will be very complicated. To simplify this problem we can thus be reduced to the linear case by making a development of Taylor to the first order, by the following formula:

$$
\nabla \hat{f}(X)=\nabla f\left(X_{k}\right)+\nabla^{2} f\left(X_{k}\right) \Delta X_{k}=0,
$$

Increment $\Delta X$ will be thus equal $a$ :

$$
\Delta X_{k}=-\left(\nabla^{2} f\left(X_{k}\right)\right)^{-1} \nabla f\left(X_{k}\right)
$$

From equations (8) and (9), we then obtain:

$$
\min \sum d_{i}^{2}=\min \left[f_{o}\left(a_{k 0}\right)+\sum_{i=1}^{n} \frac{\partial f(\varphi, \psi, h)}{\partial a_{k}} \Delta a_{k}\right]^{2}
$$

If we derive the function, $d_{i}$ compared to the parameters we will obtain:

$$
\left\{\begin{array}{c}
\Delta \psi \\
\Delta \varphi \\
\Delta h
\end{array}\right\}=\left[\begin{array}{ccc}
\Sigma\left(\frac{\partial f}{\partial \psi}\right)^{2} & \sum \frac{\partial f}{\partial \psi} \frac{\partial f}{\partial \varphi} & \sum \frac{\partial f}{\partial \psi} \frac{\partial f}{\partial h} \\
\sum \frac{\partial f}{\partial \varphi} \frac{\partial f}{\partial \psi} & \sum\left(\frac{\partial f}{\partial \varphi}\right)^{2} & \sum \frac{\partial f}{\partial \varphi} \frac{\partial f}{\partial h} \\
\sum \frac{\partial f}{\partial h} \frac{\partial f}{\partial \psi} & \sum \frac{\partial f}{\partial h} \frac{\partial f}{\partial \varphi} & \sum\left(\frac{\partial f}{\partial h}\right)^{2}
\end{array}\right]^{-1}\left[\begin{array}{ll}
-\sum f & \frac{\partial f}{\partial \psi} \\
-\sum f_{o} \frac{\partial f}{\partial \varphi} \\
-\sum f \frac{\partial f}{\partial h}
\end{array}\right]
$$

The procedure of Fig. 7, illustrates the step followed in the determination of the attributes of associated surfaces.

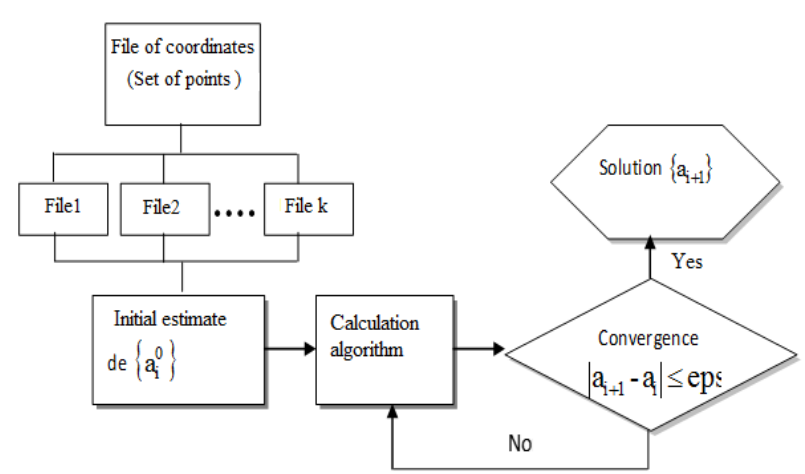

Fig. 7 Summary of the optimization process

The incrementing of at the time of each iteration makes it possible to approach solution $a^{*}$ successively. The algorithm of optimization is summarized as follows:

- To give a first $a_{0}$ estimate.

- To calculate $\Delta a_{k}$

- To calculate $a_{k+1}=a_{k}+\Delta a_{k}$

- To repeat 1 and 2 until $\nabla f\left(a_{k}\right)$ is sufficiently small.

\section{Application}

Let us consider the example of application shown in the following figure:

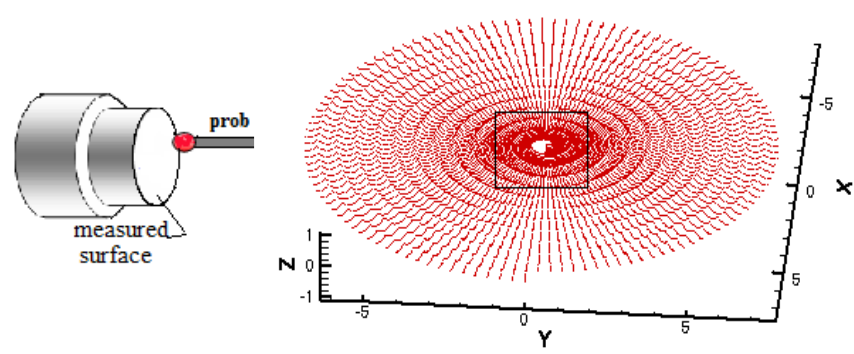

Fig. 8 Points cloud representing the measured surface

The surface obtained by machining for $f=0.8 \mathrm{~mm} / \mathrm{rev}, r_{\varepsilon}=0.4 \mathrm{~mm}$

With:

$$
r_{\varepsilon}: \text { Ray of nozzle of the tool }
$$

\section{$f$ : Advance of the tool}

We recover a file of coordinated points representing the measured surface (18000 coordinated points), from this topographical survey (Fig. 8), we have chosen six different methods of acquisition. For that, we have established a program in Visual Basic-6 software (VB-6), which consists to read this data file, and enables divide into classes, each class will contain the coordinates of measured points and through these classes, it's possible to establish some acquisitions methods( 1 to 6 ) presented in Fig. 9. 


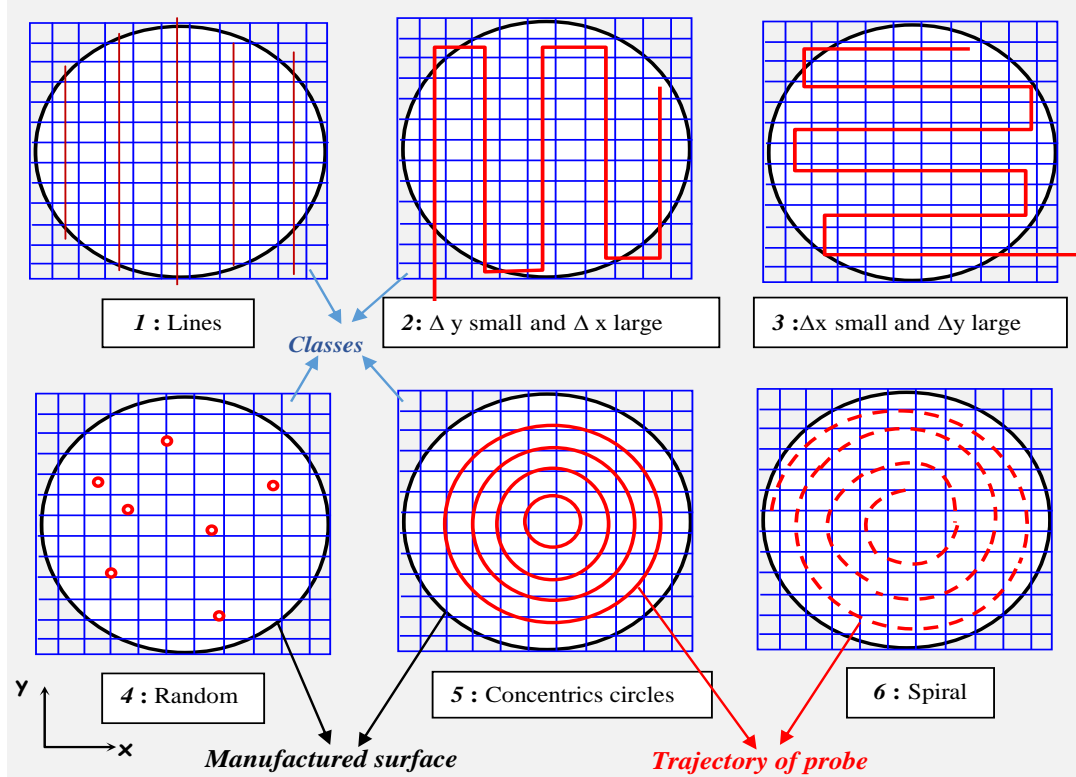

Fig. 9 Acquisition methods

\section{Results of acquisitions methods for Visual Basic-6 soft-} ware (VB-6)

The introduction of all topographic survey (points cloud) in the developed a data-processing model enables a calculation of measurement acquisition methods of the surface. The results are stored in files in txt format (Fig. 10). Thereafter, the program allows associating each points cloud a geometric surface (plan) in least squares sense and determines the parameters that characterize this surface.

The following figures show the points clouds provided by the program for each method of acquisition.

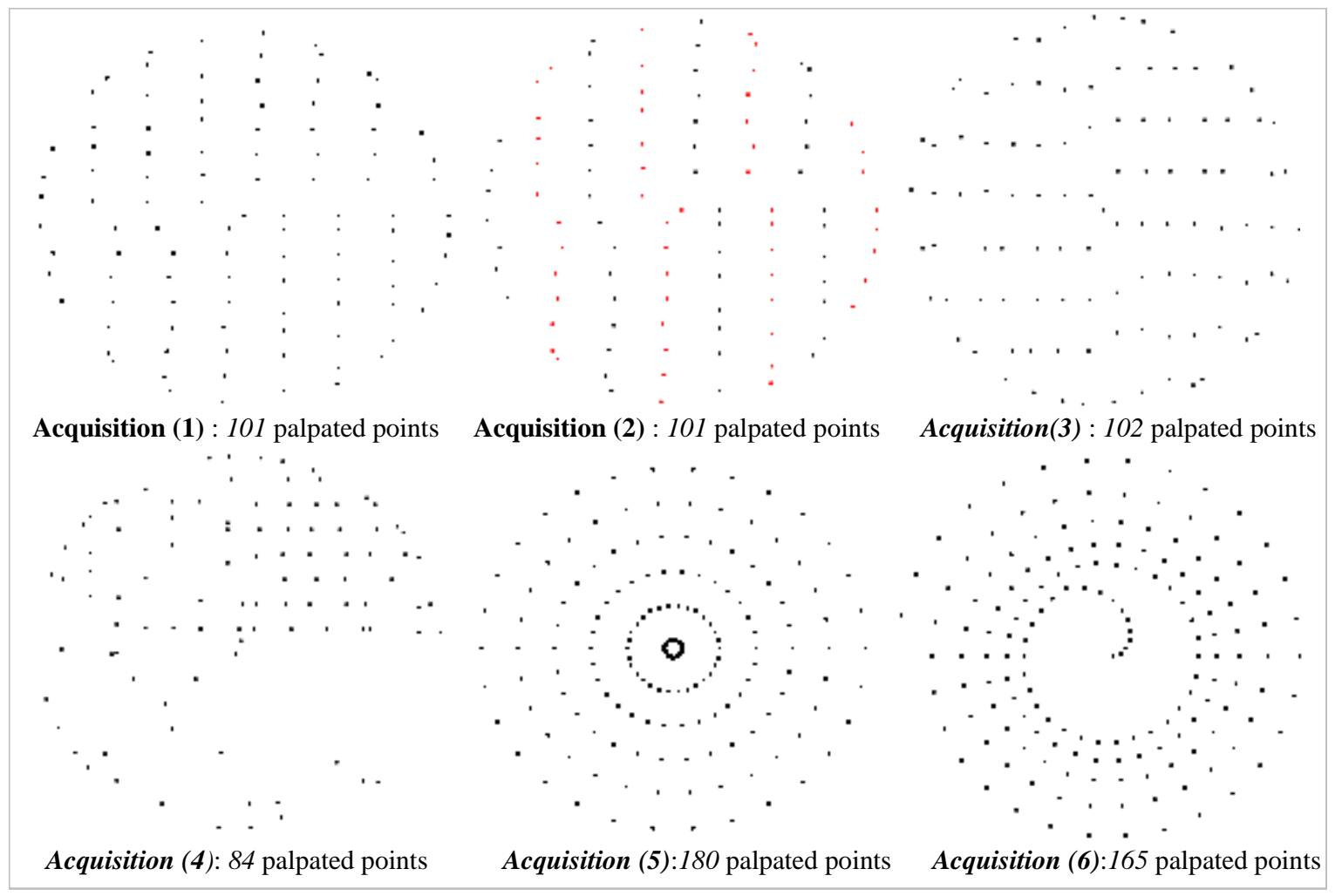

Fig. 10 Points clouds for acquisition methods (1 to 6 )

Figs. 11 and 12 illustrate a graphical representation of points cloud for both acquisition methods respec- tively 5 and 6, using the Microsoft Excel, conform to those in the Fig. 10. 


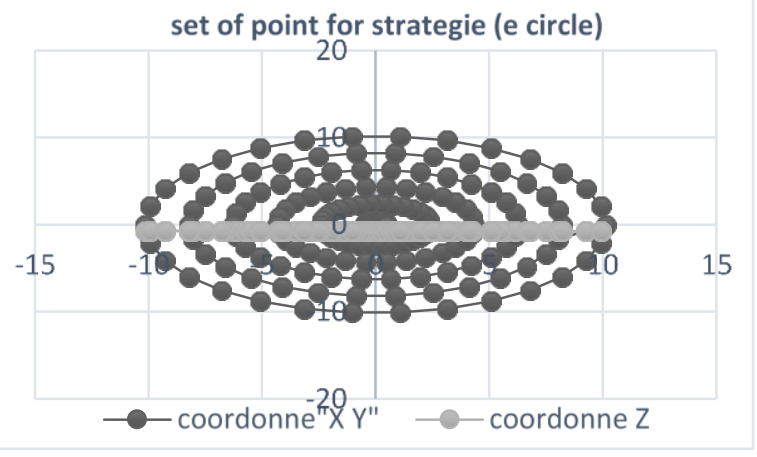

Fig. 11 The fifth acquisition by Excel software

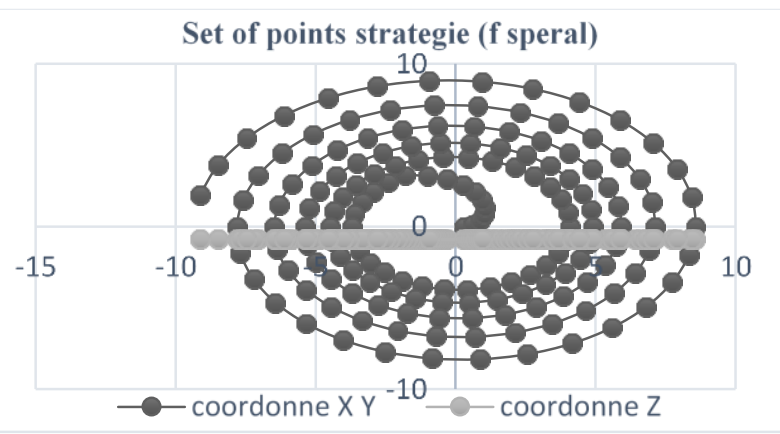

Fig. 12 The sixth acquisition by Excel software

After this acquisition phase, we proceed to search the optimal parameters of the positioning of the perfect geometrical surface in the cloud points. The result of the association enables us to evaluate mean values of the parameters of the associated surfaces. Following this, we calculate the errors on the parameters optimization mainly due to the error probing. When we used the least squares method as an optimization criterion, then the best error estimator is given by the matrix formulation (12), developed by [18, 19 and 20].

$$
\left\{U_{c}\left(a_{i}\right)\right\}=\left([A][A]^{t}\right)^{-1}[A]^{t}[B] .
$$

\subsection{Results of optimization}

The characteristics of the associated surface are shown in Tables 1,2,3,4, 5 and 6.

Table1 displays the results of the associated surface. it's made up of three columns:

- The first one proposes an estimate of the position of the center of gravity and components of the normal vector $\mathrm{V}(\mathrm{mm})$.

- The second one presents the uncertainty associated $(U c)$ with these results.

- The third column presents the defect of form $(d f)$ and their uncertainty associated $U d f$

The parameters of the 1 st method of acquisition

\begin{tabular}{|c|c|c|c|}
\hline \multirow{7}{*}{ 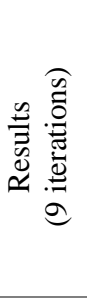 } & $\begin{array}{l}\text { Vector V and } \\
\text { center of gravity }\end{array}$ & $\begin{array}{l}\text { Uncertainty } \\
U c(\mathrm{~mm})\end{array}$ & $\begin{array}{c}\text { form defect } \\
d f(\mathrm{~mm})\end{array}$ \\
\hline & $n x=5.1019 \mathrm{E}-05$ & $\pm 2.2389 \mathrm{E}-08$ & $2.628 \mathrm{E}-02$ \\
\hline & $n y=5.009 \mathrm{E}-06$ & $\pm 2.2807 \mathrm{E}-07$ & $U d f(\mathrm{~mm})$ \\
\hline & $n z=0.9999999$ & $\pm 1.1478 \mathrm{E}-12$ & \multirow[t]{4}{*}{ $\pm 2.73 \mathrm{E}-05$} \\
\hline & $X \operatorname{cog}=0.119725$ & $\pm 1.408 \mathrm{E}-23$ & \\
\hline & $Y \operatorname{cog}=-8.72-02$ & \pm 0.000 & \\
\hline & $Z \operatorname{cog}=-0.76163$ & $\pm 2.748 \mathrm{E}-19$ & \\
\hline
\end{tabular}

Table 2

The parameters of the 2nd method of acquisition

\begin{tabular}{|c|c|c|c|}
\hline \multirow{7}{*}{ 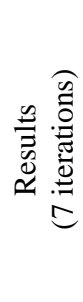 } & $\begin{array}{l}\text { Vector V and } \\
\text { center of gravity }\end{array}$ & $\begin{array}{l}\text { Uncertainty } \\
U c(\mathrm{~mm})\end{array}$ & $\begin{array}{l}\text { Form defect } \\
\qquad d f(\mathrm{~mm})\end{array}$ \\
\hline & $n x=6.5643 \mathrm{E}-05$ & $\pm 9.9737 \mathrm{E}-06$ & $2.699 \mathrm{E}-02$ \\
\hline & $n y=4.739 \mathrm{E}-05$ & $\pm 1.3813 \mathrm{E}-05$ & $U d f(\mathrm{~mm})$ \\
\hline & $n z=0.9999999$ & $\pm 8.0752 \mathrm{E}-10$ & \multirow[t]{4}{*}{ $\pm 2.79 \mathrm{E}-05$} \\
\hline & $X_{c o g}=8.48 \mathrm{E}-02$ & $\pm 4.213 \mathrm{E}-24$ & \\
\hline & $Y_{\operatorname{cog}}=-0.1821$ & \pm 0.000 & \\
\hline & $Z_{c o g}=-0.7617$ & $\pm 5.2042 \mathrm{E}-20$ & \\
\hline
\end{tabular}

Table 3

The parameters of the 3rd method of acquisition

\begin{tabular}{|c|c|c|c|}
\hline \multirow{7}{*}{ 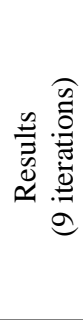 } & $\begin{array}{l}\text { Vector V and } \\
\text { center of gravity }\end{array}$ & $\begin{array}{l}\text { Uncertainty } \\
U_{C}(\mathrm{~mm})\end{array}$ & $\begin{array}{l}\text { form defect } \\
\qquad d f(\mathrm{~mm})\end{array}$ \\
\hline & $n x=-4.252 \mathrm{E}-05$ & $\pm 1.5318 \mathrm{E}-05$ & $2.650 \mathrm{E}-02$ \\
\hline & $n y=3.424 \mathrm{E}-05$ & $\pm 3.7396 \mathrm{E}-05$ & $U d f(\mathrm{~mm})$ \\
\hline & $n z=0.9999999$ & $\pm 1.6523 \mathrm{E}-09$ & \multirow[t]{4}{*}{ $\pm 3.26 \mathrm{E}-05$} \\
\hline & $X_{c o g}=4.778 \mathrm{E}-02$ & $\pm 8.363 \mathrm{E}-24$ & \\
\hline & $Y_{\text {cog }}=-0.190569$ & \pm 0.000 & \\
\hline & $Z_{c o g}=-0.762566$ & $\pm 1.5318 \mathrm{E}-19$ & \\
\hline
\end{tabular}

Table 4

The parameters of the 4th method of acquisition

\begin{tabular}{|c|c|c|c|}
\hline \multirow{7}{*}{ 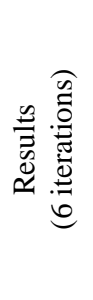 } & $\begin{array}{l}\text { Vector } \mathrm{V} \text { and } \\
\text { center of gravity }\end{array}$ & $\begin{array}{c}\text { Uncertainty } \\
U c(\mathrm{~mm})\end{array}$ & $\begin{array}{l}\text { form defect } \\
\mathrm{d} f(\mathrm{~mm})\end{array}$ \\
\hline & $n x=4.2752 \mathrm{E}-04$ & $\pm 6.279 \mathrm{E}-06$ & $3.253 \mathrm{E}-02$ \\
\hline & $n y=4.0113 \mathrm{E}-04$ & $\pm 6.377 \mathrm{E}-06$ & $U d f(\mathrm{~mm})$ \\
\hline & $n z=0.999999$ & $\pm 3.681 \mathrm{E}-09$ & \multirow[t]{4}{*}{ $\pm 1.158 \mathrm{E}-05$} \\
\hline & $X_{c o g}=-5.24532$ & $\pm 3.901 \mathrm{E}-23$ & \\
\hline & $Y_{\operatorname{cog}}=-1.670781$ & \pm 0.00 & \\
\hline & $Z_{c o g}=-0.761821$ & $\pm 6.654 \mathrm{E}-20$ & \\
\hline
\end{tabular}

Table 5

The parameters of the 5 th method of acquisition

\begin{tabular}{|c|c|c|c|}
\hline \multirow{7}{*}{ 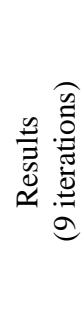 } & $\begin{array}{l}\text { Vector V and } \\
\text { center of gravity }\end{array}$ & $\begin{array}{l}\text { Uncertainty } \\
U c(\mathrm{~mm})\end{array}$ & $\begin{array}{l}\text { form defect } \\
\qquad d f(\mathrm{~mm})\end{array}$ \\
\hline & $n x=1.29721 \mathrm{E}-03$ & $\pm 1.34562 \mathrm{E}-09$ & $3.6871 \mathrm{E}-02$ \\
\hline & $n y=1.33851 \mathrm{E}-04$ & $\pm 1.31238 \mathrm{E}-08$ & $U d f(\mathrm{~mm})$ \\
\hline & $n z=0.9999991$ & $\pm 1.75483 \mathrm{E}-12$ & \multirow[t]{4}{*}{ $\pm 3.126 \mathrm{E}-08$} \\
\hline & $X_{\operatorname{cog}}=-1.577 \mathrm{E}-13$ & $\pm 2.7296 \mathrm{E}-22$ & \\
\hline & $Y_{c o g}=1.8183 \mathrm{E}-14$ & \pm 0.00 & \\
\hline & $Z_{c o g}=-0.75968$ & $\pm 2.0931 \mathrm{E}-19$ & \\
\hline
\end{tabular}

Table 6

The parameters of the 6th method of acquisition

\begin{tabular}{|c|c|c|c|}
\hline \multirow{7}{*}{ 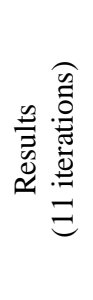 } & $\begin{array}{l}\text { Vector V and } \\
\text { center of gravity }\end{array}$ & $\begin{array}{l}\text { Uncertainty } U c \\
(\mathrm{~mm})\end{array}$ & $\begin{array}{l}\text { form defect } \\
\qquad d f(\mathrm{~mm})\end{array}$ \\
\hline & $n x=-8.990 \mathrm{E}-04$ & $\pm 3.6073 \mathrm{E}-07$ & $3.151 \mathrm{E}-02$ \\
\hline & $n y=5.999 \mathrm{E}-04$ & $\pm 5.4072 \mathrm{E}-07$ & $U d f(\mathrm{~mm})$ \\
\hline & $n z=0.9999994$ & $\pm 3.8989 \mathrm{E}-10$ & \multirow[t]{4}{*}{ $\pm 1.61 \mathrm{E}-07$} \\
\hline & $X_{c o g}=-0.046402$ & $\pm 1.6050 \mathrm{E}-22$ & \\
\hline & $Y_{c o g}=0.314929$ & \pm 0.000 & \\
\hline & $Z_{\text {cog }}=-0.753161$ & $\pm 1.4850 \mathrm{E}-19$ & \\
\hline
\end{tabular}

6.2. Discussion of results

According to the whole of results obtained, we observe that the doubts about the position of the center of gravity are largely low (zero) as the orientation vector (the normal) Fig. 13. They mainly benefit the attenuating effect 
of the extent of the surface. However, a very small difference is almost negligible was reported between the values of the uncertainty in the two respective directions $X$ and $Y$ (Fig. 14). Observe also that the uncertainties on the center of gravity in the directions $O x, O y$ are negligible (null) and that is an insignificant variation in the direction indicated Oz Fig. 13.

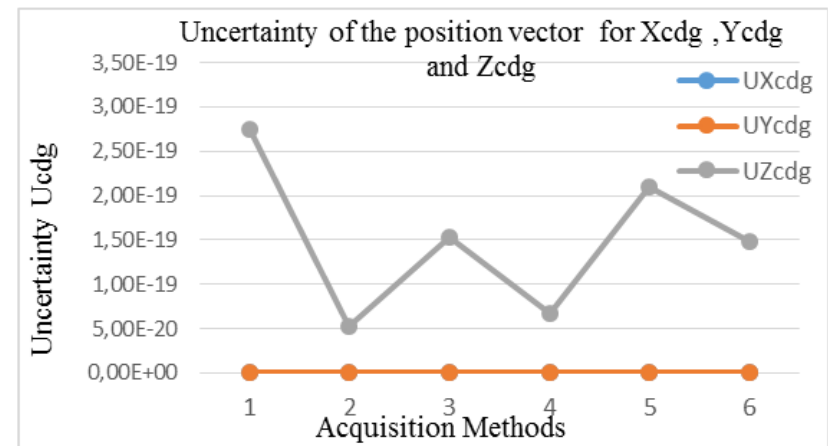

Fig. 13 Uncertainty of the position vector $X c d g, Y c d g$ and Zcdg

Uncertainty according of the normal to direction $\boldsymbol{X}$ is smaller than according to $\boldsymbol{Y}$, as shows it the Fig. 14 .

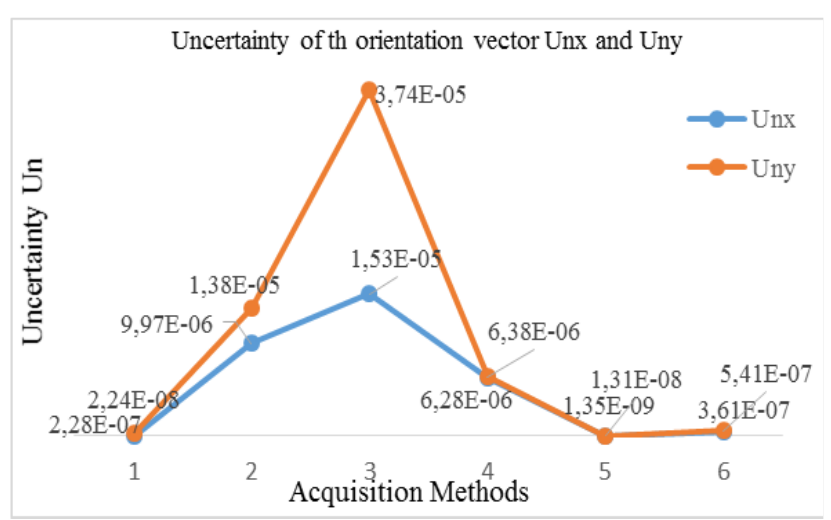

Fig. 14 Uncertainty of the orientation vector $N x, N y$

According to the results obtained, the first three strategies have almost the same number of acquired points, and the same number of the iterations, but uncertainties about the normal are not the same.

For the third strategy uncertainty on both component of the normal following the axis $X$ and $Y$ are relatively low (Fig. 14) and the component along the Z-axis for the fourth acquisition (Fig. 15). However, this shows that the strategy of acquisition has an influence on the measurement uncertainties.

The fifth and sixth acquisition (circular and spiral trajectory) show that the uncertainties are significantly lower (Fig. 16). They have a more significant precision than other strategies, and this may be due to the distribution of probed points describing the actual or measured surface.

From This study, the results of uncertainties for each strategy show that the number of points and the method of acquisition influence the result of measurement. Therefore, it is necessary to optimize the choice of acquisition method to carry out appropriate measures.

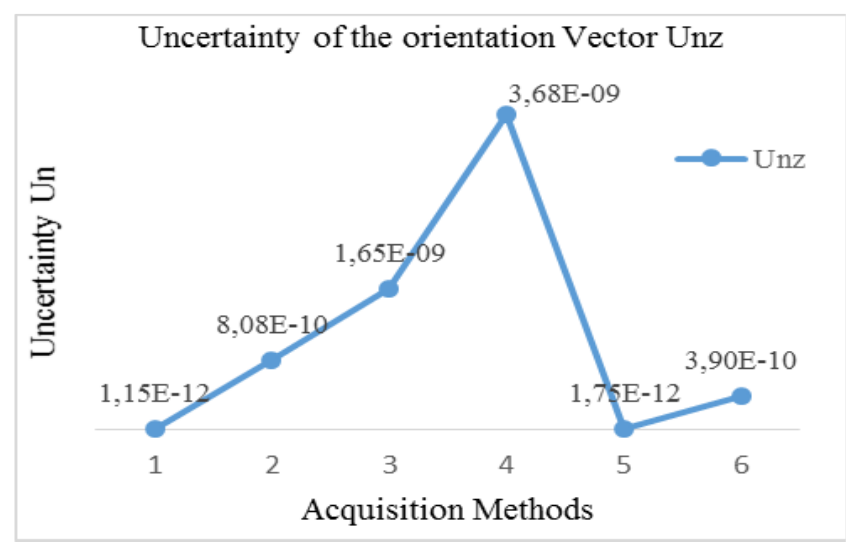

Fig.15 Uncertainty of the orientation vector for $\mathrm{Nz}$

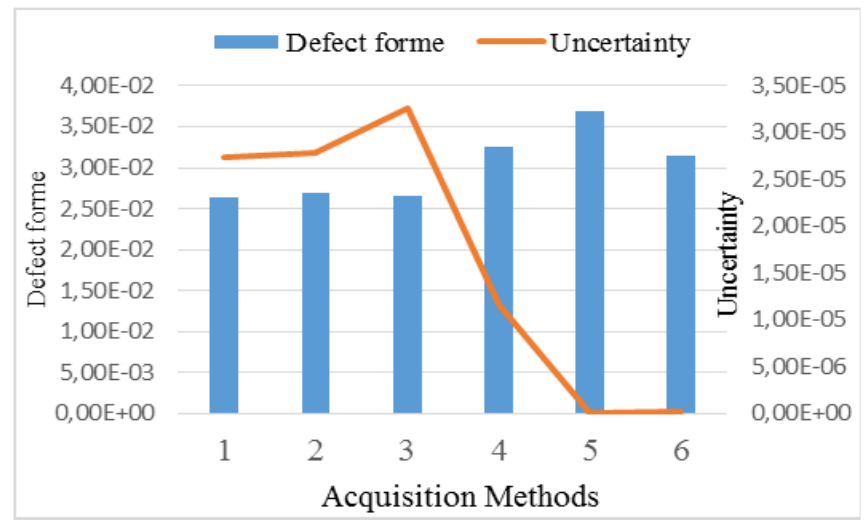

Fig. 16 The defect form and their uncertainty

\section{Conclusion}

During the measurement of a real surface by a coordinate measuring machine (CMM), The association surfaces is obtained using the minimization of the function $d_{i}$, it's the distance between the measured points and the associated surface. After optimizing this function in the sense of least squares nonlinear, we determine the parameters characterizing the associated surface. To calculate the uncertainties, it is possible to model the measurement process, but the problem is much more complex, because the measurement uncertainties accumulate to give a global error that will affect the measurement result.

In this paper, we developed a program in Visual Basic-6 software that enables us from a set of points cloud taken from a coordinate measuring machine to make some acquisitions strategy, and to estimate the parameters of the associated geometrical surface and their uncertainties.

We can conclude that the evaluation of uncertainties requires simultaneously to treat the three main structures that constitute the elementary process of measurement namely: the part (geometric form) instrument (rule of measurement, probe ... etc.) and treatment (software etc. ...) and their interfaces.

\section{References}

1. Pairel, E. 1995. Proposition of a new Semantics for Standardized Tolerencing - Principle of its verification on coordinate measuring machine, 7 th International Congress of Metrology, Pp.76-81, France.

2. Linares, J.M.; Bachmann, J.; Sprauel, J.M. 2002. Détermination des incertitudes des surfaces associées, Mécanique \& Industries 261-266, ELSEVIER. 
http://dx.doi.org/10.1016/S1296-2139(02)01164-8.

3. Furutani, R.; Ozaki, M. 2011. Uncertainty of calibration of $2 \mathrm{D}$ planar coordinate measuring machine, Measurement 45(3): 427-430. http://dx.doi.org/ 10.1016/j.measurement.2011.10.034.

4. Osawa, S.; Takatsuji, T.; Kurosawa, T. 2003. Stepgauge calibration using an interferometric coordinate measuring machine and the uncertainty. XVII IMEKO, World Congress Metrology in the 3rd Millennium, Dubrovnik, Croatia.

5. Woncheol, C.; Thomas Kurfess, R.; Jonathan, C. 1998. Sampling uncertainty in coordinate measurement data analysis, Precision Engineering 22: 153-163. http://dx.doi.org/10.1016/S0141-6359(98)00011-7.

6. Gestel, N.V. 2011. Determining measurement uncertainties of feature measurements on CMMs, these of Doctorate, Katholieke Universiteit Leuven - Faculteit Ingenieur swetenschappen Kasteelpark Arenberg 1 bus 2200, B-3001 Heverlee.

7. Manuael, H.; Lobato, P. 2011. An investigation into coordinate measuring machine task specific measurement uncertainty and automated conformance assessment of airfoil leading edge profiles, These of Doctorate in Engineered Materials for High Performance Applications in Aerospace and Related Technologies, the University of Birmingham, UK.

8. Arencibia, R.V.; Souza, C.; Henara, L.; Antonio, F. 2014. Simplified model to estimate uncertainty in CMM. J Braz. Soc. Mech. Sci. Eng DOI 10.1007/s40430-014-0157-8, Brazilian Society of Mechanical Sciences and Engineering. http://dx.doi.org/10.1007/s40430-014-0157-8.

9. Bachmann, J.; Linares, J.M.; Sprauel, J.M.; Bourdet, P. 2004. Aide in decision-making: contribution to uncertainties in three-dimensional measurement, Elsevier Precision Engineering 78-88.

10. Linares, J.M. 2007. Forum le collège français de métrologie prépare un guide. mesures 799.

11. Nafi, A. 2011. Vérification et diagnostic des machines à mesurer tridimensionnelles avec découplage machine et palpeur, Thèse de doctorat en génie mécanique école polytechnique de Montréal.

12. Michèle, D.; Priel, M.; Rivier C. De la validation des méthodes d'analyses à l'évaluation de l'incertitude des résultats de mesure, laboratoire national d'essai BNM LNE, Paris.

13. Clement, A. 1990. Principe d'Abbe généralisé. Technologie et formation 39-45.

14. Bourdet, P. 1999. Logiciels des machines à mesurer tridimensionnelle. L'École Normale Superieure de Cachan.

15. Bourdet, P.; Mathieu, L.; Lartigue, C.; Ballu, A. 1996. The concept of small displacement torsor in metrology, advanced mathematical tools in metrology. 110-122.

16. Bourdet, P.; Clement, A. 1988. A study of optimalcriteria identification based on the small-displacement screw model. Annals of the CIRP, Vol. 37/1.

17. Linares, J.M.; Bachmann, J.; Amara, I.; Sprauel, J.M. 2002. Estimation des incertitudes en métrologie tridimensionnelle, $1^{\text {er }}$ Congrès International de Mécanique Constantine, Algérie.

18. Yau, H.T. 1997.Evaluation and uncertainty analysis of vectorial tolerances, Precision Eng; 20: 123-37.
http://dx.doi.org/10.1016/S0141-6359(97)81198-1.

19. Courtois, S. 1998. Réalisation d'un logiciel de choix de plans d'expériences piloté par réseau de neurones. Séminaire de CNRIUT'98, p.209-222, Fontainebleau, France.

20. Nigam, S.D.; Guilford, J.D.; Turner, J.U. 1993. Derivation of generalized datum frames for geometric tolerance analysis, ASME Design Automation Conference Albuquerque.

\section{H. Gheribi, S. Boukebbab}

\section{THE INFLUENCE OF THE STRATEGY OF ACQUISITION ON UNCERTAINTIES OF MEASUREMENT OF A MACHINED SURFACE}

S u m m a r y

In the last, few years of many researchers tried to develop methods of determination of uncertainties in a data processing sequence of a CMM (Coordinate Measuring Machine). Measurement on a CMM is based on the association of an ideal surface to the set of palpated points via a mathematical calculation of the distances between the palpated points and itself surfaces. At the time of this stage of measurement, the results certainly are sullied with uncertainties, in this respect the step of quality fixed by the standard ISO 9000, requires with the metrologist to estimate the uncertainty with which, it obtained his measurement. During this article, we will present a data-processing model allows to estimate the parameters of surfaces associated with the set of points resulting from a coordinate measuring machine and their uncertainties, by holding account the method or the strategist of palpation. The method of conjugate gradient used to evaluate the attributes, which characterize associated surfaces, after having optimized quadratic equation $d_{i}$ (variation of form) within the meaning of nonlinear least squares. With an aim of being able to show the influence of these methods on uncertainties of measurement.

Keywords: Three-dimensional metrology, Coordinate measuring machines (CMM), optimization of associated surfaces, modelling, uncertainties of measurement, propagation.

Received March 14, 2016 Accepted June 08, 2017 